\title{
Peertechz
}

\section{Development and evaluation of} hand operated seed cleaner for small-holder farmers in East Hararghe, Oromia

Received: 12 March, 2021

Accepted: 01 May, 2021

Published: 05 May, 2021

*Corresponding author: Teshome Urge Jiru, Oromia Agricultural Research Institute, Fadis Agricultural Research Center, P. O. Box 904, Harar, Ethiopia, Tel: +256667549; Fax: +0256667551; Email: urgetash123@gmail.com

Keywords: Seed cleaner; Development; Hand operated

https://www.peertechzpublications.com

\author{
Teshome Urge Jiru ${ }^{1 *}$ and Ibsa Aliyi Usmane ${ }^{2}$ \\ ${ }^{1}$ Oromia Agricultural Research Institute, Fadis Agricultural Research Center, P. O. Box 904, Harar, \\ Ethiopia \\ ${ }^{2}$ School of Rural Development and Agricultural Innovation, Haramaya University, P.O.Box 138 Dire \\ Dawa, Ethiopia
}

\begin{abstract}
Cleaning and grading are two final operations of high-quality grain production that are traditional method cleaning \& separation of sorghum and maize. Farmers normally do by hand which have many problems. The farmers of East and West Hararghe Zones have a problem of high seed shortage to get improved seed at the right sowing time and du to absent of cleaning \&separation machine to use local seed of good variety. To reduce the problem the hand operated seed cleaner machine horizontally vibrating air-screen type was designed, fabricated and its performance was evaluated with the main parts of centrifugal blower, eccentric unit \& a set of reciprocating sieve with belt-pulley driven system. The machine separates product on the basis of the differences in their sizes and incorporate fan to remove light particles. The machine was constructed at the FARC workshop from locally available materials. The machine was tested for its cleaning efficiency \& capacity with sorghum \& maize at Damota arada and observed that, the maximum cleaning efficiency of the machine at moisture content of $18 \%$ \& 19 were $80 \%$ for sorghum and \& 90 $\%$ for Maize, and its capacity was found $5.7 \& 8.5 \mathrm{q} / \mathrm{hr}$ for sorghum \& maize respectively, which is much better than that of traditional cleaning which have observed about $0.8 \& 1.2 \mathrm{q} / \mathrm{h}$ for sorghum \& maize respectively. During the test seeds of others crop \& seeds of weeds were found below the range which is 300 \& 200 unit/kg respectively. The newly developed low production cost machine has got a promising acceptance for its higher efficiency, higher capacity and lower lab our time energy requirement and accessibility to be used both for seed cleaning, grading and commercial use, and also due to its simplicity and locally manufactured, it showed a potential for wider adoption, as a result, experiments and/or demonstrations will be continued under the local Hararghe under farmers' conditions.
\end{abstract}

\section{Introduction}

Sorghum (S. bicolor) and Maize are the most important cereal crops in eastern \& western Hararghe administration zones eastern Oromia regions. They are widely grown and consumed in almost all parts Rural and Urban Town and highlands and lowlands of the regions since majority of producers are small scale-farmers. In such a scale of farming all the operation is done manually using traditional hand tools. The traditional method of cleaning of Sorghum and Maize are normally done by using hand tools against a natural wind breeze velocity. The traditional method of cleaning has got many problems which could be expressed in terms of grain quality, grain loss and labor and time utilization $[1,2]$.
A good cleaning machine should remove all chaff straws and plant debris with very little grain loss and for better storage and higher, but in traditional method of separation often the natural wind condition may not be favorable for the operation and the result is increased time of operation and drudgery. The farmers of eastern \& western Hararghe zones have high seed shortage and have a problem of getting improved seeds at right sawing time. The Seed cleaning and grading machine exist in developed countries very expensive to buy for use and maintain for our farmers and various types of manually operated grain cleaning, and grading machines have been developed and evaluated that suitable for small and marginal farmers especially for seed purposes, but the introduction of these machines for farmers never be done \& farmers has no 
accesses to use their produced product seed of good quality of local good varieties [3].

These postharvest losses can be minimized significantly with primary processing [4]. Cleaning and grading of agricultural commodities are considered as most important primary unit operations. In design of efficient and effective cleaning and grading machines, physical properties of materials are taken into account [5]. There are quite a number of factors that affect the performance in terms of cleanliness and grain loss during the operation. Such factors include amount of wind or air velocity, feed rate, and shaker frequency, dimension of sieve opening, sieve tilt angle, crop variety and moisture content [6]. Portable cleaning \& grading machine need to reduce the improved seed shortage problems faced by farmers of eastern \& western Haraghe zones thus the primary needs of our smallholder farmers for high quality seed grain and improved seed or commercial seed products a hand operated seed grain cleaner \& grading machine was developed and evaluated.

Therefore, it is clear that there is a great initiation for new ideas and novel approaches to meet these requirements that can be used on farm level \& within the purchase power of farmers will help that, a hand operated air screen seed grain cleaning \& grading machine was designed developed and performance evaluation made on, sorghum and maize grain seed, to strengthen seed shortage problem the to stimulate agricultural production by obtaining additional market by meeting export demands, \& minimize the wide gap of technological different used by developed countries and in general the productivity of farmers will be increased.

\section{Objectives}

* To design \& develop hand operated seed grain cleaning and grading machine.

* To evaluate the performance of developed hand operated seed grain cleaning and grading machine

\section{Materials and Methods}

The following steps were considered during the design of machine:- physical properties ,terminal velocity, coefficient of frication, the arithmetic mean diameter of grain stroke length by [7] (1) \& homograph or calculating board by [7] (2) energy requirement from ergonomic data by (7 [D] (3) of machine velocity ratio by [8] was found.

\section{Design considerations}

During the fabrication of each parts of the machine all necessary design considerations as material, machine and operational factors were taken in to account. The functions of each part or component and their description are as follows to obtain the acceptable capacity and efficiency of the machine:

i. Size of screen surface The frequency amplitude selection was depend on amplitude frequency of sieve, horizontal angle \& coefficient friction two governing factors needed to be mentioned i.e. width of screen affects capacity whereas, its length affects efficiency. The width is necessary to reduce bed thickness, and the length to allow the undersize to be removed without inordinate amount of fines in the oversize. So that the size of screen was decided by considering the general rule that the length of screen should be between $2-3$ times of its width (1).

ii. Shape of the opening: the shape of screen opening depends up on the shape of grain to be handled. There for, for rounded shaped grain, the top screen of round holes and bottom screen of slotted holes were used for sorghum and for maize both rounded holes screens were used.

iii. Percentage open (perforated) area: Higher percentage open are increase both capacity and screening efficiency. To ensure good contact and maximum available use of plate area, holes were spaced as close as practicable; nevertheless, it was done that by recognizing that there was a great limitation to increase the open area. Excessive loading in terms of strength means excessive cost of replacement which might be more than the saving resulting from increased capacity (1).

iv. .A aperture size: For round openings, the size of scalping screen was decided to be slightly higher than the equivalent diameter of the grain to pass through the aperture, \& whereas size of grading screen was kept small enough to retain the smallest desirable grain.

v. Angle of inclination: Both screens where made adjustable to different degrees of inclination with horizontal plan. The common range in pith adjustable is from $4-12^{\circ}$ [8] (1). To obtain optimum capacity and efficiency, it was decided to use $12^{\circ}$ for scalper and $8^{\circ}$ for grading

\section{Centrifugal Blower}

Fan selection calculation depends upon terminal velocity of maize and sorghum where adopted by [7,9] (1) \& [7] (2) depends upon terminal velocities of sorghum $9.7 \mathrm{~m} / \mathrm{s}$ \& 11.6 $\mathrm{m} / \mathrm{s}$ for maize, chaff, leaves \& stem [1] (3) \& [10] .....(4) The air velocity need to separate the unwanted material from sorghum and maize were $9.7 \mathrm{~m} / \mathrm{s}$ and $11.6 \mathrm{~m} / \mathrm{s}$ greater than terminal velocity of the stems and leaves and less than that of each grain.

The diameter of the main driver shaft that carries driverpulley

Accessories was determined diameter of _using the expression

$d=3 \sqrt{\frac{16}{\pi \tau} T}$

where $=$ Torsional shear stress MPa

$\mathrm{T}=$ Twisting moment or Torque acting on the Shaft, Nm

The diameter of $30 \mathrm{~mm}$ stainless steel was chosen for the main shaft.

Citation: Jiru TU, Usmane IA (2021) Development and evaluation of hand operated seed cleaner for small-holder farmers in East Hararghe, Oromia. J Civil Eng Environ Sci 7(1): 018-024. DOI: https://dx.doi.org/10.17352/2455-488X.000040 
1. The rotational speed of driver pulley, rpm

$$
\boldsymbol{n} 1=\boldsymbol{n c}(1-\boldsymbol{S c})
$$

Where, nc S -0.051 factor

2. Determine the rotational torque on input shaft from ergonomic data by (8) $0.08(\mathrm{~kW})$

$$
\mathrm{T}=1000 * \mathrm{P} 1 / \mathrm{W}
$$

Where $\mathrm{T}$ - Torque in put shaft

$\mathrm{P}_{1}=$ The average output manpower of adults men from ( 0.8$)$ KW

$\mathrm{W}_{1}=$ angular speed at input shaft

$1000 \times 0.8 / 170=4.7$

3. Calculate the design diameter of the smaller pullet

Ds $=40 \sqrt{T}$

Where $d_{s}=$ smaller diameter of pulley

$40 \sqrt{27}=125 \mathrm{~mm} 40 \sqrt{ } 4.7=86 \mathrm{~mm}$

4. Compute the larger sheave diameter

$\mathrm{D}_{1}=\mathrm{d}_{\mathrm{s}} \times \mathrm{u}$

Where $\mathrm{D}_{1}=$ the larger diameter of pulley

$\mathrm{VR}=$ speed ratio

$D_{1}=125 \times 2.8=350 \quad 88 \times 5=425$

From stander we select the larger diameter of pulley D1= $460 \mathrm{~mm}$

5. Determine belt speed

$\mathrm{V}=\mathrm{W} 1 * \mathrm{D} 1 /(2+1000)$

$\mathrm{V}=125 * 1509 / 2 * 1000=7$

$125 \times 1509 /(2 \times 1000)$

$=170 \times 88 / 2 \times 1000=7.48 \mathrm{~m} / \mathrm{s}$

6. Find the angular speed of the driven shaft

$W 2=\frac{d 2 \times w 2(1-€)}{d 1 \times w 2}$

$=125 \times 150(1-0.02) / 355=54.8 \mathrm{rad} 1 / \mathrm{s}$

Where $€=0.02$ is the then amount of slippage

$\mathrm{w}_{2}=$ angular speed of the driven shaft

7. Compute the actual center distance

$\mathrm{a}=W 1 / W 2$
8. Determine the tangential force (transmitted load)

$2 * 27 * 1000 / 125=427 \mathrm{~N}$

9. Find the optimum center distance

$\operatorname{amax}=055 \mathrm{~d} 1+\mathrm{d} 2 \mathrm{~T}_{0}$

$\operatorname{amin}=d_{1}+d_{2} \quad \mathrm{a}_{\min }=\mathrm{d} 1+\mathrm{d} 2$

Where $-\mathrm{T}_{0}$ section part of belt table 7.7

10. Determine center distance

$a=0.25[L p+w]+\sqrt{(L p-w) 2}-2 y)$

Where $\mathrm{L}_{\mathrm{p}}=$ calculated length of belt

$W=0.5 \pi(d 1+d 2)$

$y=\left(d_{2}-d_{1}\right) 2$

11. Compute the angle of contact

$\alpha=180^{\circ}-57^{\circ} \frac{d 2-d 1}{a}$

$3.14(355+125) / 2=754 \mathrm{~mm}$

$\Delta 2=\frac{(d 1+d 2)^{2}}{2}$

$(355-125)^{2} / 2=13225 \mathrm{~mm} 2$

And apply to Eq.8.1) to calculate the belt length 2

$L=2 a+0.5 \pi(d 1+d 2)+\frac{(d 1+d 2) 2}{4 a}$

Round off to the neared standard value

We refine the center distance

12. Determine the rate of belt runs

$2 \times 374+754+12225 / 374=1537.4 \mathrm{~mm}$

13. Determine the rate of belt runs.

$R=\frac{1000 \times V}{L}$

$\mathrm{R}=1000 * 3.6 / 16005.85 \mathrm{~s}-{ }^{1 \mathrm{~b}} 1000 \times 3.6$

$R=\frac{1000 \times 3.6}{1600 \times 5.85 \mathrm{~S}}$

Velocity ratio $=\mathrm{N} 1 / \mathrm{N} 2=\mathrm{D} 2 / \mathrm{D} 1$

$1000 / 220.26=4.54 \therefore \mathrm{VR}=\mathrm{N} 1 / \mathrm{N} 2=\mathrm{D} 2 / \mathrm{D} 1 \mathrm{D} 2=\mathrm{VR} * \mathrm{D} 1=$ $4.54 * 550=227 \mathrm{~mm} \cong 230 \mathrm{~mm}$

Citation: Jiru TU, Usmane IA (2021) Development and evaluation of hand operated seed cleaner for small-holder farmers in East Hararghe, Oromia. J Civil Eng Environ Sci 7(1): 018-024. DOI: https://dx.doi.org/10.17352/2455-488X.000040 


\section{Determine pulley diameter belt}

The velocity ratio $(\mathrm{VR})=\mathrm{D} 1 / \mathrm{D} 2$

Where - D1 $=$ diameter of driver pulley_

D2 =_Diameter of driven pulley

$(V R)=460 / 88=5.22$, speed $-1,460 / 66=7$ speed $-2,460$ $/ 50=9$ speed -3

1. The Rpm of blower shaft $=$ rpm of driver shaft $\mathrm{x}$ diameter of driver pulley 2

Diameter of driven pulley:

$=170 * 460 / 88=888 \mathrm{rpm}$

$=200 * 460 / 66=1393$

1. The capacity of screen during design development was calculate using formula by academic Garacken, 1988). (2)

$Q=\mathrm{K} q s-\frac{m}{s^{2}}$

Where $\mathrm{k}$ = coefficient which depend on type of grain

$q=$ fedrate,$\frac{\mathrm{kg}}{\mathrm{s}^{2}}$

$S=$ correctionareaofsieve, $m^{2}$

$H_{d}=\frac{\rho v^{2}}{2}$

Where $\mathrm{v}=$ average velocity of air at inlet $\mathrm{m} / \mathrm{s}$

$\rho=$ densityofair $\mathrm{Kg} / \mathrm{cm}^{3}$

Density of air $=1.225 \mathrm{Kg} / \mathrm{cm}^{3}$

\section{Calculation of centrifugal Fan}

Calculation of centrifugal agricultural blower by academic $[11,12]$.

2. Total head $(\mathrm{H})$ from dynamic \& static $\mathrm{H}_{\mathrm{st}}$ ) pressure head

$H=H_{d}+H_{c}$

Where $=H_{d}$ dynamic pressure head

$\mathrm{H}_{\mathrm{ct}} \quad$ static pressure head

3. Static pressure head from the relationship

$H_{s}=\left(\varphi_{1}+\varphi_{2}+\ldots \ldots \ldots+\varphi_{n}\right)\left(\frac{\rho v^{2}}{2}\right)$

Where

$\varphi=$ int ernalcoffc int resis $\tan t$, whichdepandontypeof

$\rho=$ densityofair $\frac{\mathrm{kg}}{\mathrm{cm}^{3}}$
Density of air $\mathrm{kg} / \mathrm{cm} 3=1.225$

$v=$ velocity - ofairatinlet $\frac{m}{s}$

- Velocity of air with inlet hole of blower

$V_{o}=1.26 k \sqrt{H_{t}}$

$\mathrm{K}=$ coefficient - ofres $\tan e$

\section{$H_{t}=$ Theoreticalstatisic - pressure, head}

4. The diameter of air inlet hole when the entertains of air in two sides:

$D h_{o}=\sqrt{\frac{2 Q}{\pi V_{o}}}$

5 The internal diameter of blower from proportion

$\mathrm{D}_{0=}\left(1.0 \ldots 1\right.$. Do 3) $\mathrm{D}_{\mathrm{i}}$

The outer diameter of blower was calculated (1)

$$
\begin{aligned}
& D_{o}=\frac{n}{2} \sqrt{\frac{H_{t}}{\varphi \rho}} \\
& D_{o}=\frac{n}{2} \sqrt{\frac{H_{t}}{\varphi \rho}}
\end{aligned}
$$

The outer diameter of blower was calculated:

$1.53 * 10^{4} / 1440 * \sqrt{ } 4 / 1.5=450^{\prime}=450 \mathrm{~mm}$

Where $\mathrm{n}=$ rpm of blower wheel academic [11] usually equal to $(400-1000)$

$\varphi=$ coefficient of internal friction which depend on blower wheel \& working condition $=(1.5)$

6. The width of blower was taken equal to the width of sieve (2)

$$
B_{b}=B_{s}
$$

Where $\mathrm{B}_{\mathrm{b}}$ = width of blower

$B_{s}$ width of sieve

$\mathrm{B}=$ Width of sieve on the machine $(480 \mathrm{~mm})$ (Table 1$)$ (Figure 1).

Machine constriction: The hand operated seed cleaning \& grading machine was built at Fadis Agricultural Reacher center. The machine consists mainly of hopper, sieve box, crank mechanism, fan, supporting frame, and power transmission system. The feeding hopper made from $1.5 \mathrm{~mm}$ sheet metal by welding and situated on the upper portion of the supporting frame. Sieve box consists of two replicable stander metallic sieves round sieve hole $\Phi 4.5 \mathrm{~mm}$ for top \& 2 x $20 \mathrm{~mm}$ slotted bottom sieve for cleaning of sorghum and for cleaning of maize 
Table 1: Technical specification of hand operated grain cleaning and grading machine.

\begin{tabular}{|c|c|}
\hline $\begin{array}{l}\text { Type of machine } \\
\text { grain cleaner }\end{array}$ & Air screen \\
\hline \multicolumn{2}{|l|}{ Over all dimension } \\
\hline $\begin{array}{l}\mathrm{L} \times \mathrm{W} \times \mathrm{h}, \mathrm{mm} \\
\quad \times 1000\end{array}$ & $1500 \times 650$ \\
\hline Blower Type & Centrifugal \\
\hline Diameter of blower mm & 450 \\
\hline Number of blade & 8 \\
\hline $\mathrm{L} \times \mathrm{W}$ of blower blade, $\mathrm{mm}$ & $480 \times 120$ \\
\hline \multicolumn{2}{|l|}{ Sieve } \\
\hline $\begin{array}{l}\text { Top sieve } \mathrm{L} \times \mathrm{W} \mathrm{mm} \\
480\end{array}$ & $1000 x$ \\
\hline Sieve area, M2 & 0.48 \\
\hline $\begin{array}{l}\text { Bottom sieve } \mathrm{L} \times \mathrm{W}, \mathrm{mm} \\
480\end{array}$ & $1000 x$ \\
\hline Sieve area M2 & 0.48 \\
\hline Hopper capacity, kg & 41 \\
\hline $\begin{array}{l}\emptyset \text { Driver \& Driven Pulley, } \mathrm{mm} \text { for speed, } 1 \\
80\end{array}$ & $460 \&$ \\
\hline $\begin{array}{c}\emptyset \text { Driver \& Driven Pulley, } \mathrm{mm} \text { for speed,2 } \\
65\end{array}$ & $460 \&$ \\
\hline $\begin{array}{l}\emptyset \text { Driver \& Driven Pulley, mm for speed,3 } \\
50\end{array}$ & $460 \&$ \\
\hline Total Wight of machine, $\mathrm{kg}$ & 73 \\
\hline
\end{tabular}

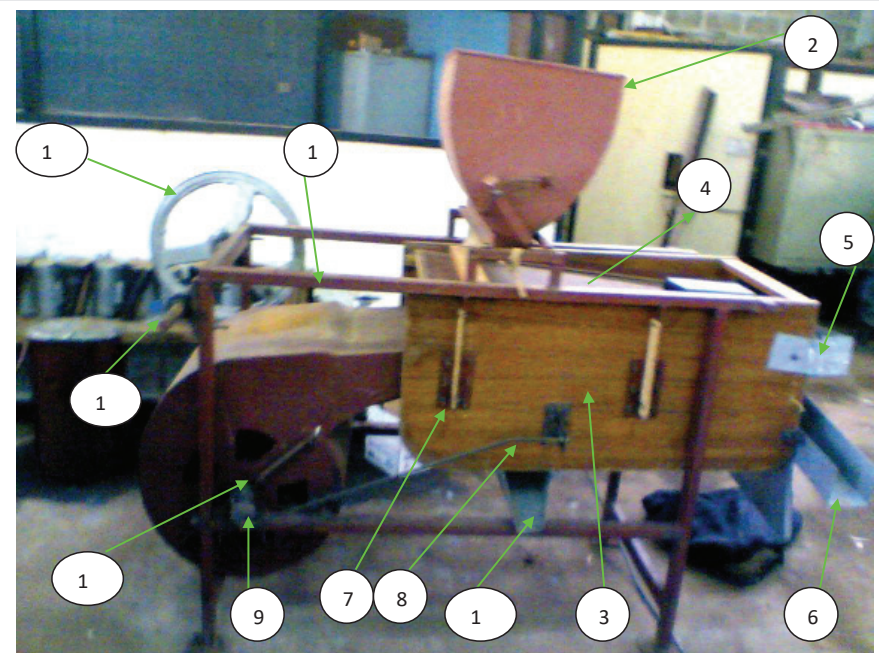

Figure 1: Schematic diagram of a hand operated- air screen grain cleaning\& grading machine.

Note: 1_rectangular supporting frames frame 2_Feed Hopper 3_Sieve box 4_Scalping or upper sieve 5_Over sized outlet 6_Clean grain outlet 7_Hangers 8_connecting rod 9_Eccentric unit 10_centrifugal blower 11_Under sized outlet 2_Handle 14_Driver Pulley.

stander metallic round sieve of hole $\Phi 12 \& \Phi 6.3 \mathrm{~mm}$ for upper $\&$ bottom sieve were arranged. Sieve box was made from a chip wood and covered with Formica to make its surfaces smooth and water proof resistance The Sieve box was tightening to supporting frame by four hanging shoe. All the outlets were mad on the sieve box. Crank mechanism with adjustable crank length and connecting rod to achieve various levels of reciprocating amplitudes was employed to drive the shaker.

Supporting frames made of rectangular pipe by welding and having $1500 \mathrm{~mm} \times$ 6 650mm x 1000mm length, width and height. The driving shaft mad from steel shaft having a diameter of $\Phi$ $30 \mathrm{~mm}$ and $900 \mathrm{~mm}$ length and fixed on back side of machine or stands with two ball bearing on each side. The driving pulley mad from double line Aluminum having diameter of $460 \mathrm{~mm}$ mounted on main shaft. The power was transmitted by rotating handle on drive pulley of by $\mathrm{v}$-belt to driven pulley on bower shaft.

A centrifugal blower type was fabricated from meld sheet metal by welding and instated on the back side lower part of rectangular frame with two ball bearing in between upper \& bottom sieve The blower housing accommodates of four straight blower blades of $160 \mathrm{~mm}$ of width and $900 \mathrm{~mm}$ length and blower shaft.

\section{The working principles of machine}

The product inters the machine through feeding hopper baffle plate with different opining size dropped on upper sieve in the sieve box. When materials to be separated. are put on vibratory screen, because of its vibration, materials are also agitated during their transit over the screen Impurities of larger size stubbles, chaff etc are retained on the top sieve \& discharged out through over size outlet. When grain \& small particles falls from upper sieve to second sieve , light materials are blown away by blower. Impurities including shrived grain, stone, soil, dust and other small materials which have weight \& smaller diameter than second sieve were separated by the second sieve \& passed through the second sieve \& dropped on the pan, discharge out through under size out let. Clean grain was retained on second sieve \& discharged out from the machine through clean grain outlet.

\section{Performance evaluation}

The performance evaluation of the design developed hand operated seed grain cleaning and grading machine was conducted using two type of seed grain i.e.- sorghum and maize. For test the machines was taken to Haramaya district in specific place known as Bate 04 Arada. In the cores of undertaking the field performance of machine human characteristics, size, weight, age, health, environmental factor \& crop condition were considered. For field testing three levels of blower speeds were obtained by changing driven pulley sizes, three stroke length by adjusting bolt and three feed rates for each grain were used. For each observation the mean of the three replications were taken for each test run, a known weight of grain was feed at a time \& the cleaning time for each test run was recorded by a stop watch. The sample grain was collected at all out let (sieve over flow, under size, clean grain and blower) out let Table 2.

The moisture contents of grain was determined using the universal moisture tester i Dole 400Model was used \& the moisture was found $18 . \%, 19 \%$ for sorghum and maize respectively, then the moisture contents of grain during threw test period has not shown change, so the moisture content of grain during the test were kept constant. For this testing purpose Maize and sorghum that had been threshed by thresher were used. The evaluation of cleaning efficiency 
Table 2: Experimental evaluation of the design developed hand operated seed grain cleaning and grading machine.

\begin{tabular}{|c|c|c|c|c|c|}
\hline No. & Variable & Level & \multicolumn{3}{|c|}{ Selection } \\
\hline 1 & Feed rate ,kg/min & 3 & 10 & 20 & 30 \\
\hline 2 & speed, $\mathrm{r}$.p. m. & 3 & $\mathbf{2 0 0}$ & $\mathbf{3 4 0}$ & $\mathbf{4 0 0}$ \\
\hline \multirow{2}{*}{3} & Stork length mm maize & 3 & 8 & 11 & 14 \\
\hline 4 & Stork length mm sorghum & 3 & 5 & 9 & 13 \\
\hline 4 & Replication & 3 & R1 & R2 & R3 \\
\hline
\end{tabular}

and cleaning capacity of the machine were analyzed, by taking sample of operation was derived as follows: In each treatment combinations of screening operation, the time of operations was measured with stop watch, the rpm of the machine was measured using digital tachometer \& samples of 100gm for sorghum \& 250gm maize weighted with electronic balance with precision of one gram from feed, clean grain, over size and undersize outlet.

Then the samples were separated manually into clean grain and impurities or foreign materials to know the fraction of material in the inlets and outlets blower out let. The machine was tested for its efficiency and capacity using normal working time length and rest period three adult persons which have the same age and body weight were used. The effectiveness of screening or cleaning efficiency for an air screen grain cleaner as suggested by the Bureau of Indian standards (BIS) (IS 5817:1980) [7,9].(21)

Cleaning Efficiency $(\%)=\frac{E(F-G)(E-F)(1-G)}{F(E-G)^{2}(1-F)}$

Where $\mathrm{E}=$ fraction of clean seed at clean seed outlet $(\%)$;

$\mathrm{F}=$ fraction of clean seed in feed, $(\%)$

$\mathrm{G}=$ fraction of clean seed at foreign mater outlet (\%)

The capacity of machine was calculated by obtained clean grain from clean grain outlet per unit time [in second] or output product rate in second multiplied by 3600 expressed in $\mathrm{Kg} / \mathrm{h}[1]$.

\section{Results and discussion}

The design developed hand operated seed grain cleaning and grading machine the average output of grain cleaner for sorghum were varied from 4.5-10 q/h with speed of 335 and $888 \mathrm{rpm}$ (speed have significant factor on out-put) maize \& 2.7- $5.7 \mathrm{q} / \mathrm{h}$. for sorghum corresponding to feed rate variation at the rated speed $\mathrm{S}_{1}, \mathrm{~S}_{2}$ and $\mathrm{S}_{3} \mathrm{rpm}$ The is because The cleaning efficiency at $(\mathrm{P}<0.05)$ for selected stroke length for each grain type 79.7 - $88.5 \%$ \& 71.5 - $83.2 \%$ for maize \& sorghum respectively corresponding to feed rate variation (nonsignificant). The feed rat weight of grain has impact on output and cleaning efficiency the machine.

The long duration test where also conducted to determine total output over long duration and break down of the machine if any, duration continues operation however, no break down was observed during this phase of trial \& the machine have got $8.5 \& 5.7 \mathrm{q} / \mathrm{h}$ for maize and for sorghum respectively performed well with high output capacity, cleaning \& separating efficiency for maize \& satisfactory for sorghum. During the test observed that training level of operator \& the efficiency of laborer responsible for conveying the crop from ground to feed hopper has greater influence on output \& efficiency of machine. The cleaning efficiency \& output capacity of the machine for maize and sorghum at different combination of variables are shown in Table 3.

\section{Conclusions and recommendations}

The overall performance of the developed machine was satisfactory that is output capacity of developed grain cleaner \& grading machine was ranged from 4.5-10 q/h for maize \& 2.7$5.7 \mathrm{q} / \mathrm{h}$ for sorghum cleaning, efficiency for maize was ranged $78-88.1 \%$ and for sorghum was ranged from $71.5^{--} 83 \%$. As machine has a promising for its cleaning efficiency \& capacity to reduce farmers' problems to be use local good variety grain for seed \& commercial propose \& the demonstration of machine should be continued under the local Hararghe on farm condition.

As performance test only on two type of grain under taken, it should be continued for different variety of grain \& including grading activity for different grain should be continued as the machine has accesses to replace a set of three sieves. To increase cleaning \& separating necessary design modifications on speed ratio of pulley \& stroke it should has to revised and more components like Bruch \& ball may be is possible to incorporate to increase the efficiency of the machine.

Table 3: The average cleaning efficiency, $\%$ and output capacity, $q / h$ hand Operated Seed cleaner for Maize.

\begin{tabular}{|c|c|c|c|c|}
\hline Stork L) mm & $\begin{array}{c}\text { Blower } \\
\text { speed (S)rpm }\end{array}$ & $\begin{array}{c}\text { Feed } \\
\mathbf{k g} / \mathbf{h a}\end{array}$ & $\begin{array}{c}\text { Output capacity } \\
\text { quintal/ha }\end{array}$ & $\begin{array}{c}\text { Cleaning } \\
\text { eff.\% }\end{array}$ \\
\hline $\mathrm{L} \mathrm{1=(17)}$ & $\mathrm{S} 1=335$ & $\mathrm{~F}_{1}$ & 4.5 & 84.5 \\
\hline
\end{tabular}

\section{References}

1. Tabatabaeefar A, Aghagoolzadeh H, Mobli H (2003) Design and Development of an auxiliary Chickpea second Sieving and Grading Machine. Agricultural Engineering international, the CIGR Journal of Scientific Research and Development. Manuscript FP 5. Link: https://bit.ly/3t6mukA

2. Teha A, Bedada T, Nur J, Aliyi I, Ketema K (2020) Pre-extension Demonstration and Evaluation of Engine Driven Sorghum Thrasher Technology in the Selected AGP-II Districts of Harari region and Dire Dawa Administration: Food Science and Quality Management 97. Link: https://bit.ly/3eIW2YV

3. Teha A, Bedada T, Ketema K, Aliyi I, Nur J (2020) Pre-extension Demonstration and Evaluation of Engine Maize Sheller Technology in the Selected AGP-II Districts of Harari Region and Dire Dawa Administration: Food Science and Quality Management 97. Link: https://bit.ly/3eJpHkH

4. Borshov T (1988) Land reclamation machinery, mir publishers, Moscow 189248 \& $256-265$.

5. Kachru R, Sahay KM (1990) Development and testing of pedal-cum power operated air screen grain cleaner: (Agricultural Mechanization in Asia), Ama 21: 29-32. Link: https://bit.ly/2Rd3bJ9

6. Sharma AP (1976) Design and development of Winnowing machine Agricultural Mechanization in Asia, Africa and Latin America 12: 25. 
7. Sahay KM, Singh KK (1994) Unit operation of Agricultural processing. Link: https://bit.ly/3eOm8ty

8. Garratt J (1996) Design and technology second edition. Link: https://bit.ly/3346WD9

9. Kachru R, Sahay KM (1990) Development and testing of pedal-cum power operated air screen grain cleaner: (Agricultural Mechanization in Asia), Ama 21: 29-32. Link: https://bit.ly/2Rd3bJ9

10. Adewumi B. Ogunlowo A, Ademosun C (2006) Investigating Particle
Trajectory as a Parameter for Selecting the Dimension of Cross Flow Grain Classifier: Agricultural Engineering International: the CIGRE Journal. Link: https://bit.ly/3aW5Aim

11. Nurul I, Ahmed KI, Moniruzzaman AKM (1980) Design and construction of manually operated seed cleaning and grading machine. Agricultural Mechanization in Asia, Africa and Latin America 11: 56-58. Link: https://bit.ly/3e6hhos

12. Kaul RN, Egbo CO, Onazi OC (1985) Introduction to agricultural mechanization: Macmillan publisher Landon and Basingstoke. Link: https://bit.ly/3347mtd

\section{Discover a bigger Impact and Visibility of your article publication with} Peertechz Publications

\section{Highlights}

* Signatory publisher of ORCID

* Signatory Publisher of DORA (San Francisco Declaration on Research Assessment)

* Articles archived in worlds' renowned service providers such as Portico, CNKI, AGRIS, TDNet, Base (Bielefeld University Library), CrossRef, Scilit, J-Gate etc.

* Journals indexed in ICMJE, SHERPA/ROMEO, Google Scholar etc.

* OAI-PMH (Open Archives Initiative Protocol for Metadata Harvesting)

* Dedicated Editorial Board for every journal

* Accurate and rapid peer-review process

* Increased citations of published articles through promotions

* Reduced timeline for article publication

Submit your articles and experience a new surge in publication services (https://www.peertechz.com/submission).

Peertechz journals wishes everlasting success in your every endeavours.

Copyright: @ 2021 Jiru TU, et al. This is an open-access article distributed under the terms of the Creative Commons Attribution License, which permits unrestricted use, distribution, and reproduction in any medium, provided the original author and source are credited.

Citation: Jiru TU, Usmane IA (2021) Development and evaluation of hand operated seed cleaner for small-holder farmers in East Hararghe, Oromia. J Civil Eng Environ Sci 7(1): 018-024. DOI: https://dx.doi.org/10.17352/2455-488X.000040 